\title{
Fusion, Disruption, and Expression of HMGA2 in Bone and Soft Tissue Chondromas
}

Anna Dahlén, Fredrik Mertens, M.D., Anders Rydholm, M.D., Otte Brosjö, M.D., Johan Wejde, M.D., Nils Mandahl, Ph.D., Ioannis Panagopoulos, Ph.D.

Department of Clinical Genetics (AD, FM, NM, IP) and Department of Orthopedics (AR), University Hospital, Lund; and Department of Orthopedics (OB) and Department of Pathology (JW), Karolinska Hospital, Stockholm, Sweden

Soft tissue and skeletal chondromas are rare entities, and only 21 cases with abnormal karyotypes have been reported. A survey of these, and 10 new cases reported herein, showed that the 12q13-15 segment is nonrandomly involved in structural rearrangements in chondromas. The HMGA2 (HMGI-C) locus in 12q15 is frequently rearranged in other benign mesenchymal tumors, and this study aimed at characterizing the expression of HMGA2 in chondromatous tumors. The material consisted of 8 soft tissue and 6 skeletal chondromas, as well as of 14 skeletal chondrosarcomas. All cases had been cytogenetically analyzed. Expression of HMGA2 could be assessed by RT-PCR in 8 chondromas and 13 chondrosarcomas. HMGA2 was expressed in 4 of six soft tissue chondromas, all displaying 12qrearrangements at cytogenetic analysis. A truncated transcript (exons 1-3), but not a full-length (exons 1-5) transcript, was detected in three of them, suggesting activation through an intragenic rearrangement. One soft tissue chondroma had a $t(3 ; 12)(q 27$; q15), and the RT-PCR analysis revealed an HMGA2$L P P$ fusion transcript, composed of $H M G A 2$ exons 1-3 and $L P P$ exons 9-11. An identical fusion transcript previously has been identified in lipoma and pulmonary chondroid hamartoma. In the fourth soft tissue chondroma, a full-length transcript was detected, indicating expression of at least one intact allele. Both skeletal chondromas expressed HMGA2. In one of them, a full-length transcript was detected, even though $12 \mathrm{q}$ was cytogenetically unaffected. A truncated or full-length transcript was

\footnotetext{
Copyright () 2003 by The United States and Canadian Academy of Pathology, Inc.

VOL. 16, NO. 11, P. 1132, 2003 Printed in the U.S.A.

Date of acceptance: July 14, 2003.

This work was supported by the Swedish Cancer Society and the Swedish Childrens' Cancer Foundation.

Address reprint requests to: Anna Dahlén, Department of Clinical Genetics, University Hospital, SE-221 85, Lund, Sweden; fax: 46461310 61; e-mail: anna.dahlen@klingen.lu.se.

DOI: $10.1097 / 01 . M P .0000092954 .42656 .94$
}

found in 8 of 13 chondrosarcomas, 4 of which displayed 12q rearrangements. Possibly, cryptic rearrangements were present among the many complex marker chromosomes in the remaining 4 cases.

KEY WORDS: Chondroma, Chondrosarcoma, FISH, HMGA2, HMGA2-LPP, RT-PCR.

Mod Pathol 2003;16(11):1132-1140

Benign cartilage tumors (enchondromas and periosteal chondromas) represent some $10-25 \%$ of all primary bone tumors. Enchondromas typically occur in the small tubular bones of the hands and feet, whereas the rare periosteal chondromas predominantly appear on the surface of the long tubular bones (1). Soft tissue chondromas (extraskeletal chondromas), which have no connection to the underlying bone or periosteum, are rare, and close to two thirds of these tumors are found in the fingers (2). The variable histological appearance of benign chondromatous tumors often makes the distinction from low-grade chondrosarcoma difficult, and clinical features and radiological findings are often needed to reach a correct diagnosis. Only 21 cytogenetically abnormal bone and soft tissue chondromas have been published (3; December 2002), restricting the possibilities of relating the clonal chromosomal aberrations to a particular pathologic subtype. Furthermore, most studies of chondromas have presented small series, with many cases showing normal karyotypes or nonclonal changes only $(4-7)$.

Chromosome region $12 \mathrm{q} 13-15$ is frequently involved in structural rearrangements in a number of benign mesenchymal tumors, such as uterine leiomyoma, lipoma, and pulmonary chondroid hamartoma, as well as in pleomorphic salivary gland adenoma (3). Molecular genetic analyses have disclosed that a common target for these rearrangements is the HMGA2 (HMGI-C) gene located in $12 \mathrm{q} 15(8-10)$. The HMGA2 protein is a member of the high-mobility group A (HMGA) proteins, 
which are small, nonhistonic, chromatinassociated proteins. These proteins are believed to affect transcription as architectural elements by bending the DNA and by interacting with a large number of other proteins, mainly transcription factors, but also to influence chromatin changes during the cell cycle (11). The HMGA2 gene is highly (and ubiquitously) expressed in embryonic tissues, but even though expression of HMGA2 has only been detected in adult kidney, lung, and synovia $(12,13), H M G A 2$ is expected to have a role in adult tissues as well (11). The HMGA2 gene has five exons, and the first three, each encoding a DNAbinding domain, are separated from the last two exons by a large intron (14). Rearrangements of HMGA2 in mesenchymal tumors often result in the in-frame fusion of the three first exons to an ectopic sequence, giving rise to a chimeric protein that may have an impact on transcription of other genes (8, $11,15)$. It has been proposed that lack of the HMGA2 3'-terminal, rather than the acquisition of new sequences, causes the altered phenotype. Indeed, expression of truncated HMGA2 is associated with gigantism and adipose tissue hyperplasia in transgenic mice (16), as well as with transformation of NIH3T3 mouse cell lines (17). However, in some tumor types, notably uterine leiomyomas, expression of a full-length transcript rather than the creation of a fusion gene is the typical outcome of 12q13-15 rearrangements (18). Furthermore, it has been shown in experimental models that also the full-length transcipt, when aberrantly expressed, may induce neoplastic growth (19). Thus, it presently seems as if both full-length and truncated HMGA2 transcripts may be oncogenic.

It has been suggested that rearrangements of chromosome bands 12q13-15 are characteristic for a subgroup of chondromas $(4,5,20,21)$, but so far the status of the HMGA2 gene has not been studied in these neoplasms. The aim of the present study was to analyze the expression of full-length and truncated HMGA2 in a series of cytogenetically analyzed soft tissue and bone chondromas. For comparison with the expression pattern in malignant chondromatous neoplasms, we also included chondrosarcomas representing different cytogenetic subgroups.

\section{MATERIALS AND METHODS}

\section{Patients}

The material consisted of 8 soft tissue and 6 skeletal chondromas, as well as 14 skeletal chondrosarcomas (Table 1). The chondroma patients (five women, nine men) were 13-74 years old (median, $53 \mathrm{y}$ ), and the chondrosarcoma patients (six women, eight men) were $28-80$ years old (median,
63 y). The chondromas represented all such tumors collected at our department during the last 15 years and from which material for expression analysis was available. The chondrosarcoma samples were selected to represent different cytogenetic subgroups (22). One (Case 15) was a peripheral chondrosarcoma, whereas the remaining 13 tumors were central. Nine tumors were classified as primary (conventional), four as dedifferentiated (Cases 23-26), and one (Case 27) as a clear cell chondrosarcoma. One chondroma and three chondrosarcomas were local recurrences; all other samples were from primary tumors.

\section{Cytogenetic Analysis}

Culturing, harvesting, and G-banding were performed as described (23), and the karyotypes were written according to the recommendations of the ISCN (24). The karyotypes of four of the chondromas and seven of the chondrosarcomas have been published $(4,7,21,22)$.

\section{RNA Extraction and cDNA Synthesis}

Total RNA was extracted from frozen tumor tissue using the Trizol-reagent according to the manufacturer' recommendations (Gibco BRL, Täby, Sweden).

For the synthesis of cDNA, 1.2-5 $\mu \mathrm{g}$ of total RNA was initially incubated for 10 minutes at $65^{\circ} \mathrm{C}$. For a $20-\mu \mathrm{L}$ reaction, a mix containing $50 \mathrm{~mm}$ Tris- $\mathrm{HCl}$, pH 8.3 (at $25^{\circ} \mathrm{C}$ ), $75 \mathrm{~mm} \mathrm{KCl}, 3 \mathrm{~mm} \mathrm{MgCl}_{2}, 10 \mathrm{~mm}$ DTT, 1 mм of each dNTP, 0.5 pм Random Hexamers, and 28 U RNAse inhibitor (RNA guard, Amersham), was then added. Finally, $400 \mathrm{U}$ of M-MLV Reverse Transcriptase (Invitrogen, Stockholm, Sweden) was added, and the reaction was incubated for 1 hour at $37^{\circ} \mathrm{C}$, followed by incubation for $5 \mathrm{~min}$ utes at $65^{\circ} \mathrm{C}$. As an internal control of cDNA quality, $1 \mu \mathrm{L}$ of cDNA was amplified by polymerase chain reaction (PCR) using Actin B-specific primers (Table 2) (25).

\section{HMGA2 Expression Analysis}

HMGA2 transcripts were detected by reversetranscribed PCR (RT-PCR), and the nucleotide sequences for all primers used are presented in Table 2. Transcripts of HMGA2 exons 1-3 were detected with primers HMG848(F) and HMG1021(R). Transcripts for $H M G A 2$ exons 1-5 were detected with primers HMG848(F) and HMG1169(R).

For the PCR, $1 \mu \mathrm{L}$ of single-stranded cDNA was used as a template. The $50-\mu \mathrm{L}$ reaction contained $20 \mathrm{~mm}$ Tris-HCl, $50 \mathrm{~mm} \mathrm{KCl}, 1.25 \mathrm{~mm} \mathrm{MgCl}_{2}, 0.8 \mathrm{~mm}$ dNTPs, $0.5 \mu \mathrm{M}$ of each primer, and $1 \mathrm{U}$ Platinum Taq DNA Polymerase (Invitrogen). Denaturation for 5 minutes at $95^{\circ} \mathrm{C}$ was followed by 35 cycles of 30 


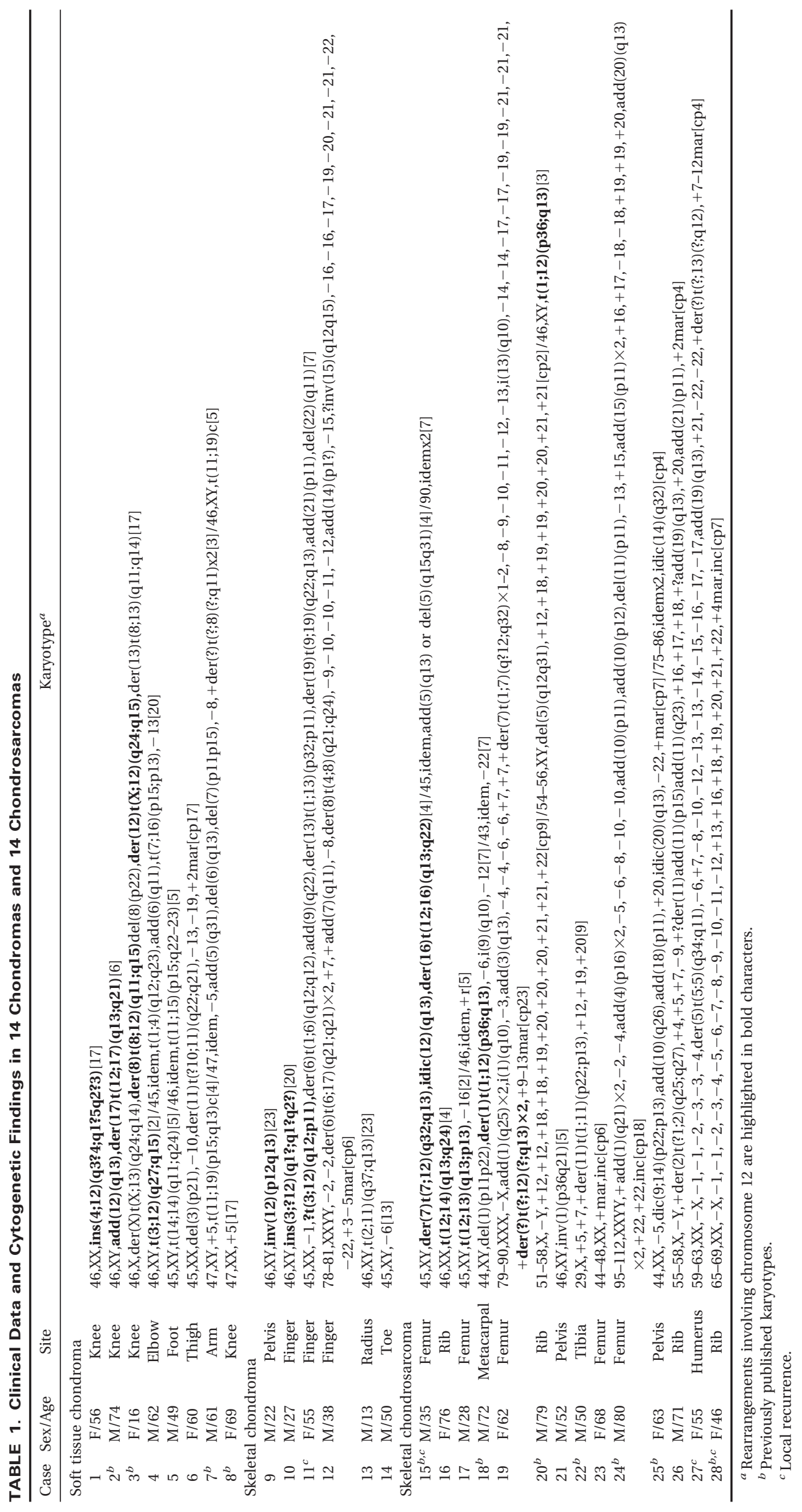


TABLE 2. Oligonucleotide Sequence Data of Primers for RT-PCR

\begin{tabular}{llc}
\hline \multicolumn{1}{c}{ Name $^{a}$} & \multicolumn{1}{c}{ Sequence } & Nucleotides \\
\hline ACTIN(F) & 5'-CCTCGCCTTTGCCGATCC & $277-294$ \\
ACTIN(R) & 5'-GGATCTTCATGAGGTAGTCAGTC & $2242-2220$ \\
HMG848(F) & 5'-ACTTCAGCCCAGGGACAA & $848-865$ \\
HMG878(F) & 5'-GCGCCTCAGAAGAGAGGAC & M10277 \\
HMG1021(R) & 5'-GGCCGTTTTTCTCCAGTG & U28749 \\
HMG1169(R) & 5'-TCCCTTCAAAAGATCCAACTGCTGC & U28749 \\
LPP1980(R) & 5'-GGGTAGCAGCCTTGGTTATCTCCT & U28749 \\
LPP2064(R) & 5'-CTAAAGGTCAGTGCTCGCCTTG & U28749-11021 \\
\hline
\end{tabular}

${ }^{a}$ Primer orientation: $(\mathrm{F})=$ forward, $(\mathrm{R})=$ reverse.

seconds at $95^{\circ} \mathrm{C}, 30$ seconds at $59^{\circ} \mathrm{C}$, and 1 minute at $70^{\circ} \mathrm{C}$. The PCR products were analyzed on a $2 \%$ agarose gel with ethidium bromide. A lipoma with a $\mathrm{t}(3 ; 12)$ translocation resulting in an HMGA2-LPP fusion and cultured amniocytes were used as positive controls for expression of exons 1-3 and exons $1-5$, respectively.

\section{Detection of HMGA2-LPP Fusion}

A chondroma (Case 4$)$ with a $(3 ; 12)(\mathrm{q} 27 ; \mathrm{q} 15)$ was analyzed for the presence of an HMGA2-LPP fusion. The primers HMG848(F) and LPP2064(R), located on exon 1 of $H M G A 2$ and exon 11 of $L P P$, respectively, were used in the first PCR amplification. One microliter of the first PCR products was amplified in a second PCR using the HMG878(F) and LPP1980(R) primers. The conditions for the PCR were the same as described above. The PCR product corresponding to the expected fusion transcript was excised, purified using the QIAquick Gel Extraction Kit (Qiagen, Hilden, Germany), and sequenced in a $20-\mu \mathrm{L}$ reaction containing the primers HMG878(F) and LPP1980(R), respectively, using the dideoxy procedure with an ABI Prism BigDye terminator cycle sequencing ready reaction kit on the Applied Biosystems Model 310 DNA sequencing system. The corresponding sequences of HMGA2 and $L P P$ were identified by a BLAST search (http://www.ncbi.nlm.nih.gov/blast).

\section{FISH Analysis}

For the characterization of $12 \mathrm{q}$ rearrangements, the cosmids $142 \mathrm{H} 1$ and 27E12, containing exons 1-2 and 4-5, respectively, of $H M G A 2$, were used (15). A whole chromosome painting probe (Vysis, Downers Grove, IL) was also used to unequivocally identify material from chromosome 12 . The cosmid probes were labeled with FluorX-dCTP (Amersham) and biotin-16-dUTP (Roche, Mannheim, Germany), using the Megaprime DNA labeling kit (Amersham), purified in a sepharose column before being dissolved in $50 \%$ formamide in $2 \times$ SSC hybridization solution to a final concentration of $20 \mathrm{ng} / \mu \mathrm{L}$. The slides for FISH were treated as described elsewhere (26).

\section{RESULTS}

\section{Expression of HMGA2}

The yield of extracted RNA from the tumor samples was low, but cDNA of sufficient quality, based on expression of Actin B, could be synthesized from 8 chondromas and 12 chondrosarcomas. A sample was not scored as positive for HMGA2 expression unless a PCR product was detected twice.

Expression of HMGA2 was detected in four of six soft tissue chondromas and in the two skeletal chondromas (Fig. 1; Table 3). Among the soft tissue chondromas, one case expressed a full-length (exons 1-5) transcript, and three cases expressed a truncated (exons 1-3) transcript. All four positive cases displayed rearrangements of chromosome arm $12 \mathrm{q}$ at cytogenetic analysis. Both cases of skeletal chondroma expressed HMGA2. Case 9, with a pericentric inv(12), expressed a truncated transcript; case 13, without any cytogenetically distinguishable involvement of $12 \mathrm{q}$, expressed a fulllength transcript. Expression of HMGA2 was detected in 8 of 12 chondrosarcomas, as a fulllength transcript in three of them and as a truncated transcript in the other five (Table 3). Of the eight positive cases, three displayed rearrangements of chromosome arm 12q at G-band analysis.

\section{HMGA2-LPP Fusion}

PCR with HMG848(F) and LPP2064(R) combination amplified weakly a 642-bp cDNA fragment in

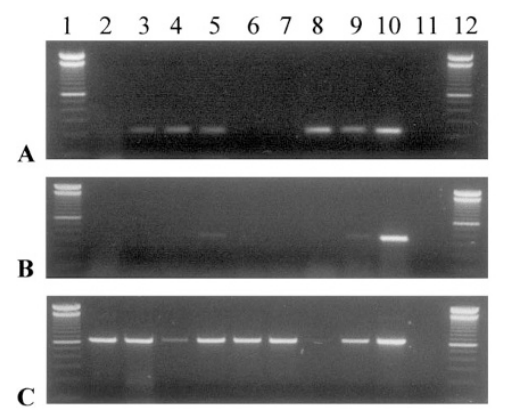

$\begin{array}{ll}1 & \text { 100-bp ladder } \\ 2 & \text { Case } 4 \\ 3 & \text { Case 1 } \\ 4 & \text { Case 2 } \\ 5 & \text { Case 3 } \\ 6 & \text { Case } 6 \\ 7 & \text { Case } 8 \\ 8 & \text { Case } 9 \\ 9 & \text { Case 13 } \\ 10 & \text { Positive control } \\ 11 & \text { Blank } \\ 12 & \text { 100-bp ladder }\end{array}$

FIGURE 1. Representative RT-PCR results of HMGA2 expression. A, amplification of exons 1-3 (191 kb), using primers HMG848(F) and HMG1021(R). B, amplification of exons 1-5 (346 bp), using primers HMG848(F) and HMG1169(R). C, all cases included expressed Actin B. 


\begin{tabular}{|c|c|c|c|}
\hline \multirow{2}{*}{ Case } & \multirow{2}{*}{ 12q13-15 Rearrangement } & \multicolumn{2}{|c|}{ HMGA2 } \\
\hline & & Exons $1-3$ & Exons $1-5$ \\
\hline \multicolumn{4}{|c|}{ Soft tissue chondroma } \\
\hline 4 & $\mathrm{t}(3 ; 12)(\mathrm{q} 27 ; \mathrm{q} 15)$ & + & - \\
\hline 1 & ins(4;12)(q3?4;q1?5q2?3) & + & - \\
\hline 2 & $\operatorname{add}(12)(q 13), \operatorname{der}(17) \mathrm{t}(12 ; 17)(\mathrm{q} 13 ; \mathrm{q} 21)$ & + & - \\
\hline 3 & $\operatorname{der}(8) \mathrm{t}(8 ; 12)(\mathrm{q} 11 ; \mathrm{q} 15) \operatorname{del}(8)(\mathrm{p} 22), \operatorname{der}(12) \mathrm{t}(\mathrm{X} ; 12)(\mathrm{q} 24 ; \mathrm{q} 15)$ & + & + \\
\hline 6 & & - & - \\
\hline 8 & & - & - \\
\hline \multicolumn{4}{|c|}{ Skeletal chondroma } \\
\hline 9 & $\operatorname{inv}(12)(p 12 q 13)$ & + & - \\
\hline 13 & & + & + \\
\hline \multicolumn{4}{|c|}{ Skeletal chondrosarcoma } \\
\hline 17 & $\mathrm{t}(12 ; 13)(\mathrm{q} 13 ; \mathrm{p} 13)$ & + & - \\
\hline 20 & $\mathrm{t}(1 ; 12)(\mathrm{p} 36 ; \mathrm{q} 13)$ & + & - \\
\hline 24 & & + & - \\
\hline 25 & & + & - \\
\hline 27 & & + & - \\
\hline 19 & $+\operatorname{der}(?) \mathrm{t}(? ; 12)(? ; \mathrm{q} 13) \times 2$ & + & + \\
\hline 21 & & + & + \\
\hline 23 & & + & + \\
\hline 16 & $\mathrm{t}(12 ; 14)(\mathrm{q} 13 ; \mathrm{q} 24)$ & - & - \\
\hline 18 & $\operatorname{der}(1) t(1 ; 12)(p 36 ; q 13)$ & - & - \\
\hline 22 & & - & - \\
\hline 26 & & $\mathrm{NC}$ & NC \\
\hline 28 & & - & - \\
\hline
\end{tabular}

$a_{+}=$expression; $-=$no expression; $\mathrm{NC}=$ not conclusive.

Case 4 , carrying a clone with a $\mathrm{t}(3 ; 12)(\mathrm{q} 27 ; \mathrm{q} 15)$ as the sole cytogenetic change. Nested PCR with a HMG878(F) and LPP1980(R) primer combination amplified strongly a 530-bp fragment (data not shown). Sequencing of the fusion transcript showed that it was composed of exons 1-3 of HMGA2 and exons 9-11 of $L P P$ (Fig. 2), suggesting that the translocation breakpoints were located in intron 3 of $H M G A 2$ and intron 8 of $L P P$.

\section{FISH Analysis}

To test for rearrangements of $H M G A 2$, a pair of cosmids was used in the four cases in which metaphase spreads for FISH were available. In Case 1, with insertion of $12 \mathrm{q}$ material into chromosome 4 , the signals from the two probes were split; $142 \mathrm{H} 1$ hybridized to the der(12) and 27E12 to the der(4) (Fig. 3). In the other three cases (5, 13, and 15), no rearrangement could be detected.

\section{DISCUSSION}

Based on the observations that chromosome bands 12q13-15 are nonrandomly involved in structural chromosome abnormalities in chondromas and that the HMGA2 locus is the target for chromosome 12 rearrangements in several other benign mesenchymal tumors, we decided to assess the status of the HMGA2 gene in a series of bone and soft tissue chondromas. Whereas transcriptional activation of HMGA2 could be demonstrated in six of eight of the cases, the mechanisms behind
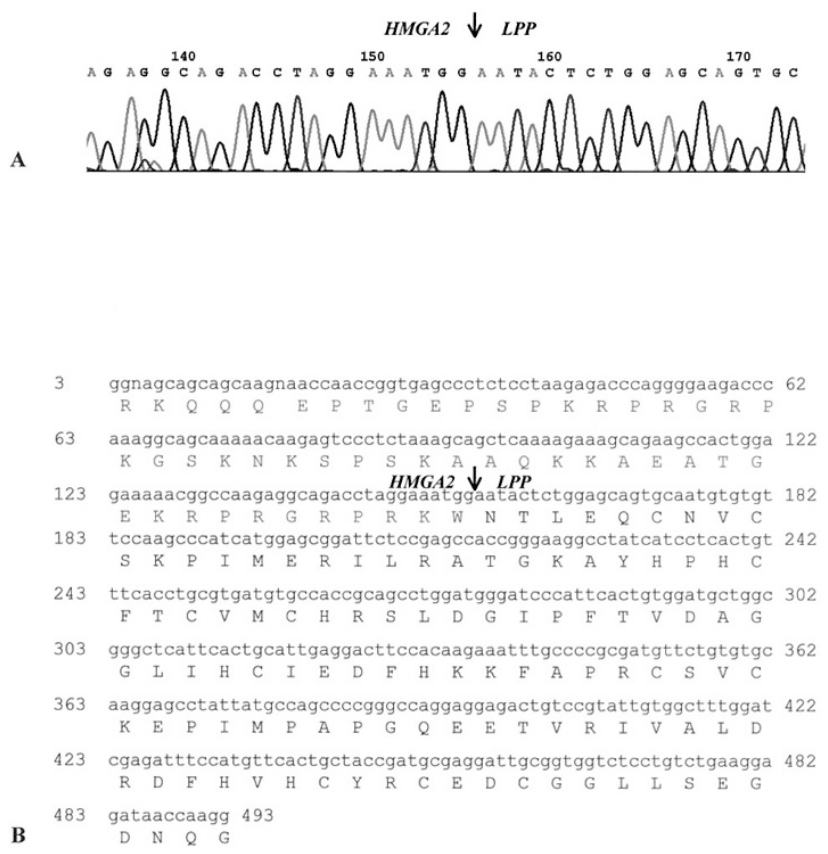

FIGURE 2. A, partial chromatogram sequence showing the fusion, indicated by an arrow, between exon 3 of HMGA2 and exon 9 of LPP. B, complete sequence of the HMGA2-LPP fusion transcript detected by RT-PCR in Case 4. Nucleotides 3-155 correspond to nucleotides 9091060 of HMGA2 (U28749), and nucleotides 156-493 correspond to nucleotides 1657-1994 of LPP (NM_005578). The amino acid sequence is indicated in capital letters.

this seem to vary among chondromas. In the present study, expression of HMGA2 was in most cases associated with cytogenetically detectable rearrangements involving 12q13-15, but transcripts were also detected in one case without any micro- 

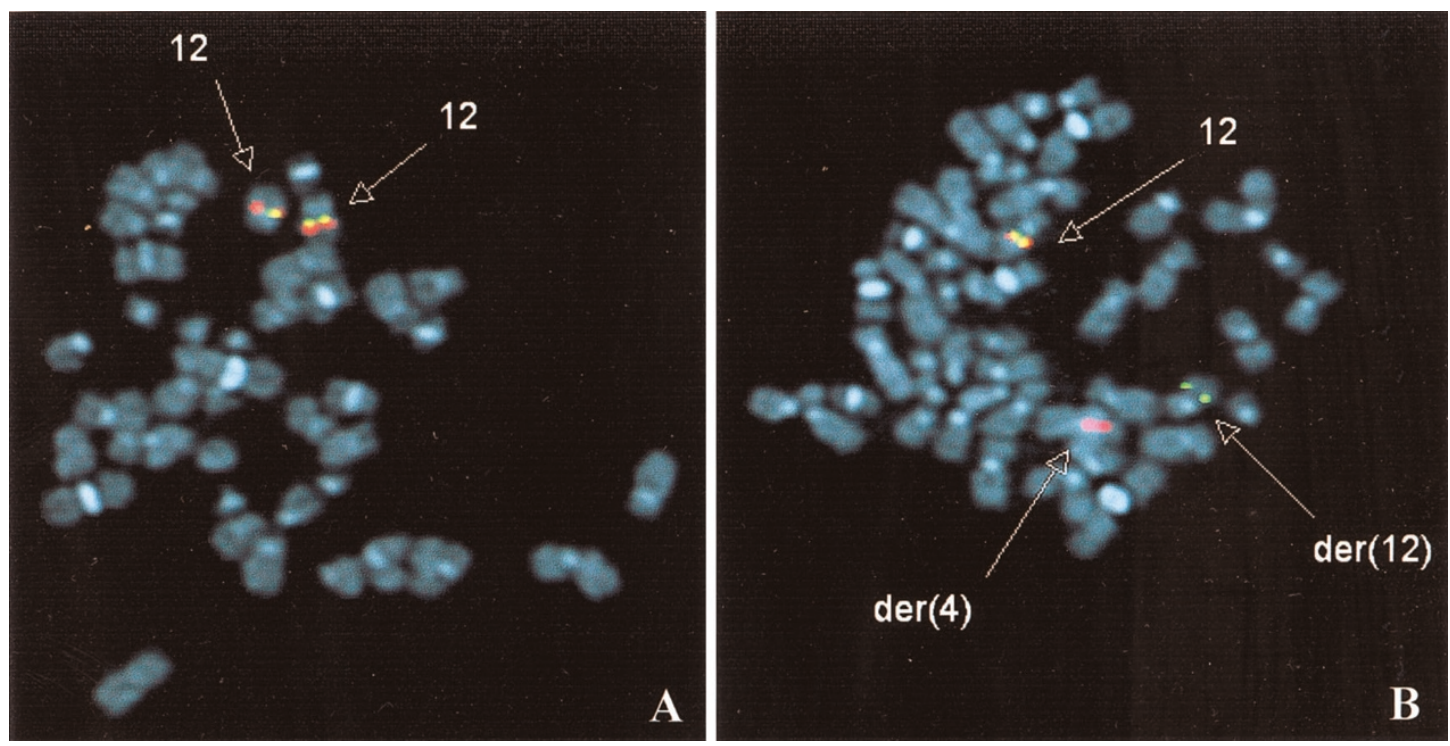

FIGURE 3. Metaphase FISH of Case 1 with an intragenic rearrangement of HMGA2. The cosmids probes $142 \mathrm{H} 1$ (green) and $27 \mathrm{E} 12$ (red) hybridize to exons 1-2 and exons 4-5 of HMGA2, respectively. A, normal metaphase. B, metaphase with an ins(4;12), in which the signal of $142 \mathrm{H1}$ is seen on der(12) and the signal of 27E12, on der(4).

scopically detectable involvement of chromosome 12. A survey of all published karyotypes, as well as of 10 previously unpublished karyotypes included in this study, showed that in addition to the recurrent involvement of 12q13-15 in chondromas, gain of chromosome 5 material; loss of material from chromosomes $6,13,19$, and 22; as well as rearrangement of band $6 \mathrm{q} 13$ are relatively common in these tumors (Fig. 4). Thus, it has to be considered that other mechanisms, besides rearrangements of 12q13-15, could be of importance in benign chondromatous tumors.

In one of the soft tissue chondromas (Case 4), we found a $\mathrm{t}(3 ; 12)(\mathrm{q} 27 ; \mathrm{q} 15)$ at cytogenetic analysis. The same translocation has been identified elsewhere as a recurrent aberration in ordinary lipoma and pulmonary chondroid hamartoma, and for both tumor types it has been demonstrated that it results in a fusion gene consisting of the first three exons of $H M G A 2$ and exons 9-11 of $\operatorname{LPP}(27,28)$. The finding of an identical gene fusion in a soft tissue chondroma emphasizes the previous notion that it is not the gene fusion as such that is decisive for tumor cell differentiation. Clearly, the morphology may vary from an entirely adipocytic differentiation (lipoma), over mixed fatty and cartilaginous differentiation (pulmonary chondroid hamartoma), to predominantly cartilaginous phenotype (soft tissue chondroma). Case 4 displayed areas of adipose tissue, but the histopathologic features were more compatible with chondroma than with lipoma with metaplastic cartilage (chondrolipoma) or chondroid lipomas. Chondroid lipomas seem to be characterized by a $\mathrm{t}(11 ; 16)$, rather than $12 \mathrm{q} 13-15$ rearrangements. However, only two cases with clonal chromosome aberrations have been reported (29, 30), and the expression status of HMGA2 has not yet been investigated in this tumor type. To our knowledge, no karyotype of chondrolipoma has been published to date, impeding any histocytogenetic correlation. Interestingly, a rearrangement of the HMGA2 locus, as part of a complex translocation involving chromosomes 2,12 , and 15 , was recently reported in one case of chondrolipoangioma (31), further emphasizing the role of HMGA2 in benign soft tissue tumors showing mixed adipose and cartilaginous differentiation.

A chromosomal exchange leading to intragenic rearrangement of $H M G A 2$ was the likely cause of transcriptional activation also in two other soft tissue chondromas. Both had rearrangements of the 12q13-15 region at cytogenetic analysis, and in both cases expression of only a truncated transcript was found. In one of these two chondromas (Case 1), FISH analysis showed that the cytogenetically observed ins $(4 ; 12)$ indeed resulted in a separation of the 5' and 3' parts of HMGA2. The finding of a full-length transcript in the fourth soft tissue chondroma with 12q13-15 rearrangement is also consistent with activation through a chromosomal rearrangement. Expression of the entire HMGA2 gene has been shown to be achieved through alterations affecting 5' regulatory elements or the 3 ' untranslated region, leading to a stabilized mRNA $(32,33)$. However, it should be noted that some tumors apparently express both full-length and truncated HMGA2 transcripts (34). Unfortunately, no metaphase spreads for FISH analysis were available from that case, and we can thus not formally exclude the possibility of an intragenic rearrangement. 


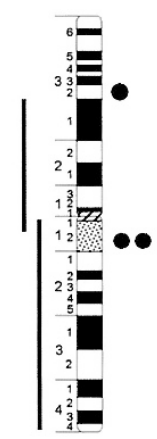

1

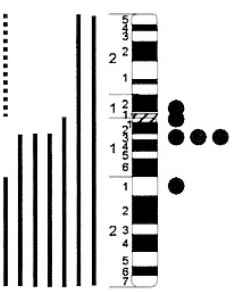

6

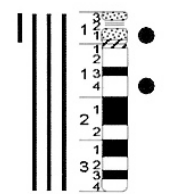

13

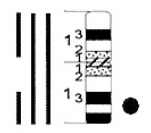

19

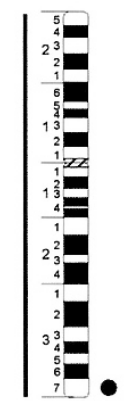

2

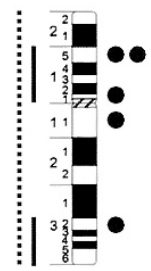

7

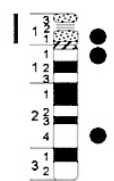

14

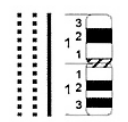

20

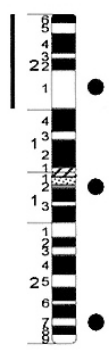

3

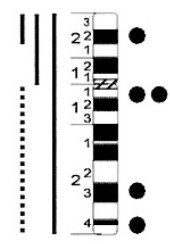

8

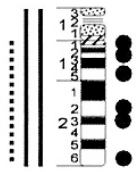

15

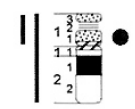

21

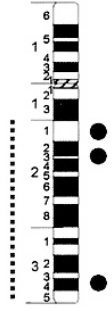

4

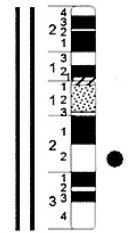

9

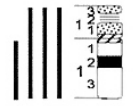

22

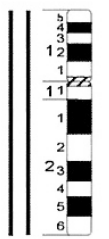

10

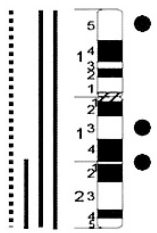

11

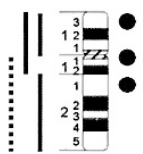

17

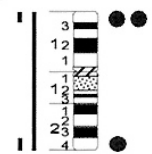

16

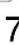

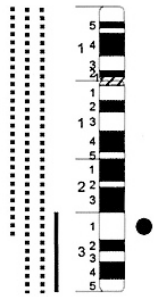

5

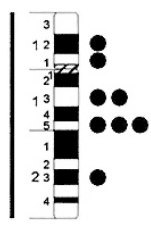

12

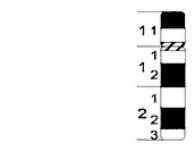

18

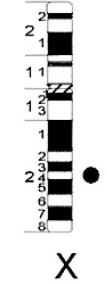

FIGURE 4. Ideogram showing the distribution of chromosomal gains (dotted lines), losses (solid lines), and breakpoints (dots) in 25 chondromas, including cases in the present study and previously published cases (3).

Two soft tissue chondromas without cytogenetically detectable $12 \mathrm{q}$ rearrangements did not show any signs of $H M G A 2$ activation at RT-PCR analysis. Thus, in the sense that HMGA2 expression was seen in all cases with 12q13-15 rearrangements, but not in any of the cases without such cytogenetic aberrations, there was complete correspondence between cytogenetic and RT-PCR results among the soft tissue chondromas. For the two skeletal chondromas that could be analyzed at the transcription level, a discrepancy between the results at the transcription and chromosome levels was observed. In one case (Case 9), showing a pericentric inversion of chromosome 12, HMGA2 expression of a truncated transcript could be detected, suggesting a similar activating mechanism as described for soft tissue chondromas. However, in the other (Case 13), a full-length HMGA2 transcript was seen despite the fact that no rearrangement of chromosome arm $12 \mathrm{q}$ or the HMGA2 locus could be detected at G-band or FISH analysis, respectively. The findings in this latter case are difficult to explain, but activation of HMGA2 possibly could have been achieved through a cryptic rearrangement affecting regulatory sequences or, alternatively, a tumor subpopulation with $H M G A 2$ rearrangement could have been lost during cell culturing, thus escaping detection at cytogenetic and FISH analysis.

Eight of 12 chondrosarcomas, all of which were of skeletal origin, expressed HMGA2, but there was no clear correspondence between chromosomal findings and expression status. HMGA2 transcripts were equally frequent among chondrosarcomas with (three of five cases) or without (five of seven cases) 12q13-15 rearrangements. Absence of HMGA2 expression in chondrosarcomas with $12 \mathrm{q}$ rearrangements may be explained by the poor resolution of chromosome-banding analysis, that is, the observed breakpoint on $12 \mathrm{q}$ might be far outside the HMGA2 locus. For the chondrosarcomas with expression of $H M G A 2$ without cytogenetically visible $12 \mathrm{q}$ rearrangements, on the other hand, one needs also to bear in mind that the karyotypes generally were much more complex than those in the chon- 
dromas. Thus, it could not be excluded that involvement of the HMGA2 locus was hidden among the many marker chromosomes that were seen in most of the chondrosarcomas with HMGA2 expression.

Our observations show that the HMGA2 gene is a frequent target for chromosomal rearrangements in chondromatous tumors and that the mechanisms behind the transcriptional activation vary. In general, HMGA2 expression was low, sometimes barely detectable, but no attempt to quantify the activity was made. Whether this low expression is due to a low RNA yield from the neoplastic parenchyma, or whether HMGA2 is active only in a subpopulation of tumor cells, was not determined within the range of the present study. However, as expression of full-length or truncated HMGA2 transcripts were common both among benign and malignant lesions, analysis of this gene, be it at the DNA or RNA level, does not seem to be useful for differential diagnostic purposes.

Acknowledgments: The authors thank Margareth Isaksson and Carin Lassen for expert technical assistance.

\section{REFERENCES}

1. Lucas DR, Bridge JA. Chondromas: enchondroma, periosteal chondroma, and enchondromatosis. In: Fletcher CDM, Unni KK, Mertens F, editors. World Health Organization classification of tumours. Pathology and genetics of tumours of soft tissue and bone. Lyon, France: IARC Press; 2002. p. 237-40.

2. Nayler S, Heim S. Soft tissue chondroma. In: Fletcher CDM, Unni KK, Mertens F, editors. World Health Organization classification of tumours. Pathology and genetics of tumours of soft tissue and bone. Lyon, France: IARC Press; 2002. p. $180-1$.

3. Mitelman F, Johansson B, Mertens F, editors. Mitelman database of chromosome aberrations in cancer. Available at: http://cgap.nci.nih.gov/Chromosomes/Mitelman. 2002.

4. Mandahl N, Heim S, Arheden K, Rydholm A, Willén H, Mitelman F. Chromosomal rearrangements in chondromatous tumors. Cancer 1990;65:242-8.

5. Bridge JA, Persons DL, Neff JR, Bhatia P. Clonal karyotypic aberrations in enchondromas. Cancer Detect Prev 1992;16: 215-9.

6. Bridge JA, Bhatia PS, Anderson JR, Neff JR. Biological and clinical significance of cytogenetic and molecular cytogenetic abnormalities in benign and malignant cartilaginous lesions. Cancer Genet Cytogenet 1993;69:79-90.

7. Tallini G, Dorfman H, Brys P, Dal Cin P, De Wever I, Fletcher CDM, et al. Correlation between clinicopathological features and karyotype in 100 cartilaginous and chordoid tumours. A report from the Chromosomes and Morphology (CHAMP) Colloborative Study Group. J Pathol 2002;196:194-203.

8. Ashar HR, Shoenberg Fejzo M, Tkachenko A, Zhou X, Fletcher JA, Weremowicz S, et al. Disruption of the architectural factor HMGI-C: DNA-binding AT hook motifs fused in lipomas to distinct transcriptional regulatory domains. Cell 1995;82:57-65.

9. Hennig Y, Wanschura S, Deichert U, Bartnitzke S, Bullerdiek J. Rearrangements of the high mobility group protein family genes and the molecular genetic origin of uterine leiomyomas and endometrial polyps. Mol Hum Reprod 1996;2:27783.

10. Kazmierczak B, Rosigkeit J, Wanschura S, Meyer-Bolte K, Van de Ven WJM, Kayser K, et al. HMGI-C rearrangements as the molecular basis for the majority of pulmonary chondroid hamartomas: a survey of 30 tumors. Oncogene 1996;12:51521.

11. Reeves R. Molecular biology of HMGA proteins: hubs of nuclear function. Gene 2001;277:63-81.

12. Gattas GJF, Quade BJ, Nowak RA, Morton CC. HMGIC expression in human adult and fetal tissues and in uterine leiomyomata. Genes Chromosomes Cancer 1999;25:316-22.

13. Broberg K, Tallini G, Höglund M, Lindstrand A, ToksvigLarsen S, Mertens F. The tumor-associated gene HMGIC is expressed in normal and osteoarthritis-affected synovia. Mod Pathol 2001;14:311-7.

14. Hess JL. Chromosomal translocations in benign mesenchymal tumors. The HMGI proteins. Am J Clin Pathol 1998;109: 251-61.

15. Schoenmakers EFPM, Wanschura S, Mols R, Bullerdiek J, Van den Berghe H, Van de Ven WJM. Recurrent rearrangements in the high mobility group protein gene, $H M G I-C$, in benign mesenchymal tumours. Nat Genet 1995;10:436-44.

16. Battista S, Fidanza V, Fedele M, Klein-Szanto AJP, Outwater $\mathrm{E}$, Brunner $\mathrm{H}$, et al. The expression of a truncated HMGI-C gene induces gigantism associated with lipomatosis. Cancer Res 1999;59:4793-7.

17. Fedele M, Berlingieri MT, Scala S, Chiariotti L, Viglietto G, Rippel V, et al. Truncated and chimeric HMGI-C genes induces neoplastic transformation of NIH3T3 murine fibroblasts. Oncogene 1998;17:413-8.

18. Quade BJ, Weremowicz S, Neskey DM, Vanni R, Ladd C, Dal Cin $\mathrm{P}$, et al. Fusion transcripts involving HMGA2 are not a common molecular mechanism in uterine leiomyomata with rearrangements in 12q15. Cancer Res 2003;63:1351-8.

19. Fedele M, Battista S, Kenyon L, Baldassare G, Fidanza V, Klein-Szanto AJ, et al. Overexpression of the HMGA2 gene in transgenic mice lead to the onset of pituitary adenomas. Oncogene 2002;21:3190-8.

20. Mandahl N, Willén H, Rydholm A, Heim S, Mitelman F. Rearrangement of band q13 on both chromosomes 12 in periosteal chondroma. Genes Chromosomes Cancer 1993;6: 121-3.

21. Mertens F, Jonsson K, Willén H, Rydholm A, Kreicbergs A, Eriksson L, et al. Chromosome rearrangements in synovial chondromatous lesions. Br J Cancer 1996;74:251-4.

22. Mandahl N, Gustafson P, Mertens F, Åkerman M, Baldetorp $\mathrm{B}$, Gisselsson D, et al. Cytogenetic aberrations and their prognostic impact in chondrosarcoma. Genes Chromosomes Cancer 2002;33:188-200.

23. Mandahl N. Methods in solid tumor cytogenetics. In: Rooney DE, editor. Cytogenetics: malignancy and acquired abnormalities. 3rd ed. New York: Oxford University Press; 2001. p. 165-203.

24. ISCN. An international system for human cytogenetic nomenclature. Mitelman F, editor. Basel, Switzerland: Karger; 1995.

25. Raff T, van der Giet M, Endemann D, Wiederholt T, Paul M. Design and testing of $\beta$-actin primers for RT-PCR that do not co-amplify processed pseudogenes. Biotechniques 1997;23: 456-60.

26. Dahlén A, Debiec-Rychter M, Pedeutour F, Domanski HA, Höglund M, Bauer HCF, et al. Clustering of deletions on chromosome 13 in benign and low-malignant lipomatous tumors. Int J Cancer 2003;103:616-23.

27. Petit MMR, Mols R, Schoenmakers EFPM, Mandahl N, Van de Ven WJM. LPP, the preferred fusion partner gene of 
HMGIC in lipomas, is a novel member of the LIM protein gene family. Genomics 1996;36:118-29.

28. Rogalla P, Lemke I, Kazmierczak B, Bullerdiek J. An identical HMGIC-LPP fusion transcript is consistently expressed in pulmonary chondroid hamartomas with $\mathrm{t}(3 ; 12)$ (q27-28; q1415). Genes Chromosomes Cancer 2000;29:363-6.

29. Gisselsson D, Domanski HA, Höglund M, Carlén B, Mertens $\mathrm{F}$, Willén $\mathrm{H}$, et al. Unique cytological features and chromosome aberrations in chondroid lipoma. A case report based on fine-needle aspiration cytology, histopathology, electron microscopy, chromosome banding, and molecular cytogenetics. Am J Surg Pathol 1999;23:1300-4.

30. Thomson TA, Horsman D, Bainbridge TC. Cytogenetic and cytologic features of chondroid lipoma of soft tissue. Mod Pathol 1999;12:88-91.
31. Van Dorpe J, Dal Cin P, Weremowicz S, Van Leuven F, de Wever I, Van den Berghe $\mathrm{H}$, et al. Translocation of the HMGI-C (HMGA2) gene in a benign mesenchymoma (chondrolipoangioma). Virchows Arch 2002;440:485-90.

32. Schoenberg Fejzo M, Ashar HR, Krauter KS, Powell WL, Rein MS, Weremowicz S, et al. Translocation breakpoints upstream of the HMGIC gene in uterine leiomyomata suggest dysregulation of this gene by a mechanism different from that in lipomas. Genes Chromosomes Cancer 1996;17:1-6.

33. Borrman L, Wilkening S, Bullerdiek J. The expression of HMGA genes is regulated by their 3'UTR. Oncogene 2001;20:4537-41.

34. Tkachenko A, Ashar HR, Meloni AM, Sandberg AA, Chada KK. Misexpression of disrupted HMGI architectural factors activates alternative pathways of tumorigenesis. Cancer Res 1997;57:2276-80. 